\title{
Analyzing and Investigating the Effect of Nailing on Stabilization Soil Trenches of Sand with Medium Density via Analytical Limit Equilibrium
}

\author{
Y. Vafa Shalmani ${ }^{1} \&$ A. Cheshomi ${ }^{1}$ \\ ${ }^{1}$ Master Graduated of Engineering Geology, Tehran University, College of Science, Department of Geology, Part \\ of Geology of Engineering, Iran \\ ${ }^{2}$ Assistant Professor of Tehran University, College of Science, Department of Geology, Part of Geology of \\ Engineering, Iran \\ Correspondence: Y. Vafa Shalmani, Master Graduated of Engineering Geology, Tehran University, College of \\ Science, Department of Geology, Part of Geology of Engineering, Iran. E-mail: yousefvafa@gmail.com
}

Received: January 12, 2016

Accepted: February 25, 2016

Online Published: March 18, 2016

doi:10.5539/mas.v10n6p1

URL: http://dx.doi.org/10.5539/mas.v10n6p1

\begin{abstract}
Pit stability in urban areas is one of the great problems of enforcement operations. A variety of methods have been devised to fixate and stabilize slopes and pits that Nailing is an example of them that is used in urban areas. In this study, stability of pit has been analyzed using this method and using the S-Nail software that the analysis has been done with limit equilibrium method. In order to investigate the effect of stabilization Nail element in sandy soil with medium density, in both dry and moist conditions, a number of used variables related to soil strength parameters such as $\mathrm{C}$ and $\varphi$ and a number used variable of related element such as the length of the Nail, are horizontal distance of elements from each other, grid or density were considered. So the effect of each variable in the soil stabilization has been obtained and resulting in proposing optimal scheme of the considered soil stabilization.
\end{abstract}

Keywords: nailing, limit equilibrium, stabilization, sandy, optimal scheme

\section{Introduction}

Pit stability in urban areas is one of the great problems of enforcement operations. Varieties of methods have been devised to fixate and stabilize slopes and pits and have been used throughout the world in variety of projects. That from them can mention: the implementation of bored pile walls, braced sheet pile, implementation of retaining walls, implementation of stable slope in the parapet, Berm implementation, nailing, and Anchorage. (Lazarte C. et al., / 2003)

Space limitations in urban areas reduce some of these mentioned methods regarding to implementation problems related to each of them. For example the braced sheet pile method because of the infrastructure installation existence in urban areas and make vibration and noise due to sheet piles bracing creates restrictions. Methods of retaining walls implementation, inclined and Berm implementation are also considered less due to space restrictions of workshop in urban areas and space necessary for deployment of machinery and equipment, and are used more in road construction projects to stabilize the parapet of the margin of these Methods. So today between these methods of stability of mentioned pit, two methods of Nailing and Anchorage are considered and used more. (Bang S., and Chung Y., / 1999)

\section{Aim of Paper}

The overall objective of this paper is to examine and analyze the behavior of nail (Nail), its impact on the stability of sandy soil with medium density, according to the effective parameters of the soil and element.

And according to analysis obtained from each variable, it is concluded that the effect of which of the parameters is more, and causes more optimal schema in terms of density, volume of executive operations and economic saving. 


\section{Research Method}

S-Nail software is analytical software with limit equilibrium method which was used in order to analyze and investigate the mentioned variables. Modus operandi is that a soil type, very loose sand have been considered at depths of 10, 20 and 30 meters pits, in dry or humid conditions with a corresponding resistive characteristics (C and $\varphi$ ) which is taken from the book Handbook of geotechnical investigation, and the corresponding elements are implemented with the vector panel. In addition to taking into account the characteristics of the soil resistance, variables related to nails such as length, horizontal and vertical distance to each other are also considered in the analysis. (. 2010 Pratap Singh V., and Sivakumar Babu G.L.,) (Hatef. 2005)

\section{Findings}

Parapets nailing means reinforced available soil in situ with steel rebars installed close together, along with the cement grout injection on an inclined surface or in excavation location, and by implementing from top to bottom. (FHWA 2003) In this way, after the excavation to a stable depth, the metal mesh has been placed on the parapet and then be Shotcrete. The next stage is drilling of pits with 50 to $200 \mathrm{~mm}$ in diameter and putting rebars (the diameter of about 20 to $40 \mathrm{~mm}$ ) in pre- determined locations, and filling the remaining of the pit with cement grout. (Hatef, 2005) Figure 1 shows the implementation of the nailing wall system.

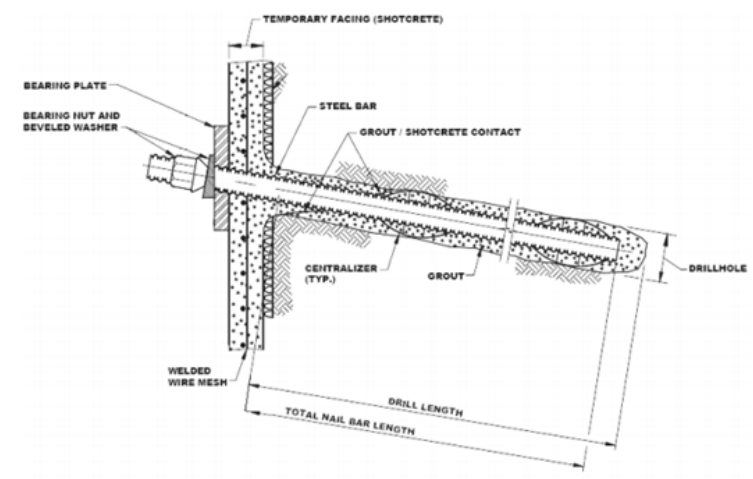

Figure 1. The implementation of the nailing wall system (FHWA 2003)

The rebars in this method are used as agents of reinforcement in order to deal with soil deformation are used. In this term, concurrently with soil transformation, the applied nailing system distributes force in the soil, and produce resistant force by bearing tensile force. Nailing parapets starts acting using soil motive pressure. Thus they need lateral displacement for mobilization of the motive force. The advantages of protection system from pit with nailing method compared to other methods of the pit parapets protecting that is implemented from top to bottom, can point to following cases: (Hagen 1998)

1. This method creates the least disorder in the traffic load of the surrounding streets.

2. Its implementation will follow the minimum occupied work space at the pit floor. On the other hand, it does not need to apply metal support systems inside the pits.

3. In this method, there is no need to locate and bury any structural elements to below the pit floor balance.

4. Implementation of soil nailing operation is fast and economical.

5. Different places and angles for nails can be used in order to avoid interference with underground facility and adjacent vital conduits.

6. Concurrent implementation of stabilization operations and excavation from top to down is in terms of stages.

7. Flexibility of nailing wall system resulted in creating appropriate behavior in the event of a general or relative great subsidence. Also the flexibility of system improves the behavior of soil profile exposing to seismic loads.

In this method, rebars help soil as a factor of reinforcement to deal with deformation. In fact, concurrent with the deformation of soil, the applied nailing system distributes force in the soil, and causes the resistance state creation in the soil with bearing tensile force. For external stability, the soil system accompanied with applied nailing must be resistant against the sliding, overturning or general rupture. Therefore, the friction force of mortar and soil helps to increase soil bearing capacity and meanwhile creates good cover for protection against corrosion around the armature. Figure (2-12) shows the image of protection pit in stabilization method with 
nailing method. (Reniz 1994)

Carlos and Lazarte in examining of a nailing parapet, its performance is mainly influenced by the interaction between its main constructor components (local soil, resistance factor (Nails and facade). In addition other variable factors such as: the construction stages, nailing method, the relationship between the nails and work facade influence the behavior of nailing parapet. (Carlos \& Lazarte, 2003)

Seo et al. (2010) with investigating the amount of movement in three different sites that have been stabilized by nailing method, have been determined some relations to obtain the amount of parapet movement based on coefficient of parapet height, and he knows the amount of general movement between $0.15 \%$ to $0.30 \%$ of total height of the excavated parapet. (Seo et al. 2010)

Byrne et al. (1998) have determined the amount of movement in weathered rock and dense soil, $0.1 \% \mathrm{H}$ or less, and for granular soil to $0.2 \% \mathrm{H}$, and for fine-grained clay soil to $0.4 \%$. (Byrne et al. 1998)

Lazarte and colleagues (2003) have known the maximum movement of the parapet on top of its and have stated that this movement is reduced gradually toward the toe parapet. Also they have known the maximum allowable movement less than $0.005 \mathrm{H}$ is. (Lazarte ET al.2003)

\section{Modeling and Analysis}

Strength parameters of $\mathrm{C}$ and $\varphi$ intended for supposed soil in different situations are as follows: (Table 1)

Table 1. Soil engineering parameters

\begin{tabular}{ccccccc}
\hline ROW & Soil type & $\begin{array}{c}\text { Dry weight per } \\
\text { unit volume } \\
\left(\mathrm{KN} / \mathrm{m}^{3}\right)\end{array}$ & $\begin{array}{c}\text { Saturation unit } \\
\text { volume } \\
\left(\mathrm{KN} / \mathrm{m}^{3}\right)\end{array}$ & $\begin{array}{c}\mathbf{E} \\
(\mathrm{Mpa})\end{array}$ & $\boldsymbol{\phi}$ & $\begin{array}{c}\mathbf{C} \\
\left(\mathrm{KN} / \mathrm{m}^{2}\right)\end{array}$ \\
\hline 1 & Medium dense sand & 17 & 20 & $8-30$ & $32-37$ & $0-2$ \\
\hline
\end{tabular}

\section{Pit depth of 10 meters:}

Authorized length of nail (Nail) depending on what in the regulation of FHWA (2003) expressed is between 0.6H to $1 \mathrm{H}$ at the depth of 6 meters pit to be at least this amount. (H times the depth of the pit with unit of meters).

\section{Dry state:}

In order to check the stability of the soil based on resistive characteristics of $C$ and $\varphi$, excavation and panel-taking without the implementation of stabilization element (Table 2), in the program were taken run definition (Figure 2), the results of which are as follows:

Table 2. Relating to unreinforced soil

\begin{tabular}{cccc}
\hline Row & $\varphi$ & $\mathrm{C}\left(\mathrm{KN} / \mathrm{m}^{2}\right)$ & F.S \\
\hline 1 & 32 & 1 & 0.17 \\
2 & 37 & 2 & 0.07 \\
\hline
\end{tabular}




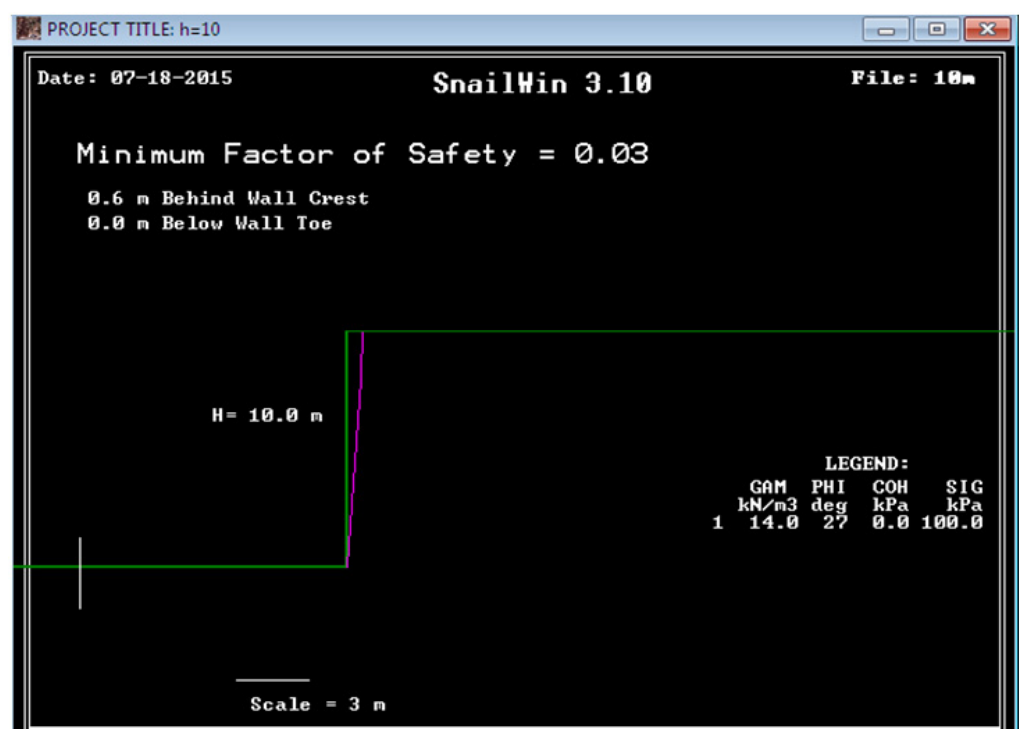

Figure 2. An example of soil analysis in the dry state at the unreinforced conditions - S-Nail software

Table 3 shows analyzes conducted about the soil desired:

Table 3. Analysis relating to the applying elements

\begin{tabular}{ccccccc}
\hline Row & $\begin{array}{r}\text { length of } \\
\text { Nail (m) }\end{array}$ & Grid / density & $\phi$ & $\begin{array}{c}\mathrm{C} \\
\left(\mathrm{KN} / \mathrm{m}^{2}\right)\end{array}$ & $\begin{array}{c}\text { Bond stress } \\
(\mathrm{kPa})\end{array}$ & F.S \\
\hline 1 & & & 32 & 0 & & 0.84 \\
2 & 6 & $2 \times 2$ & 37 & 0 & & 0.96 \\
3 & & & 37 & 2 & & 100 \\
4 & 6 & $1 \times 1$ & 32 & 0 & & 1.43 \\
5 & 6 & & 37 & 2 & & 1.05 \\
6 & 10 & $2 \times 2$ & 37 & 2 & 150 & 1.11 \\
7 & 12 & & 37 & 2 & & 1.11 \\
8 & 16 & & 37 & 2 & & 1.11 \\
\hline
\end{tabular}

From the Table 3 can be found that initially modeling was conducted based on minimum soil resistive parameters defined and variables increased due to the lack of desired confidence coefficient defined and reached to the maximum value defined for mentioned soil desired that desired confidence coefficient was not provided, ultimately.

It should be noted that initially density of applying Nails has been $2 \times 2$ it was trying to obtain with minimum density of stability necessary that this important continued by increasing the length of Nails but F.S obtained has been less than the acceptable amount. As a result Nails increased and changed to $1 \mathrm{x} 1$ grids that in this case, the desired confidence coefficient was achieved by the minimum of soil resistive parameters.

\section{Applying the water level:}

First soil was investigated in the case of unreinforced that its detailed is observable in Table 4 and Figure 3:

Table 4. Check the stability of unreinforced soil

\begin{tabular}{cccc}
\hline Row & $\varphi$ & $\mathrm{C}\left(\mathrm{KN} / \mathrm{m}^{2}\right)$ & F.S \\
\hline 1 & 32 & 1 & 0.16 \\
2 & 37 & 2 & 0.24 \\
\hline
\end{tabular}


Table 5 shows carried out analysis about the desired soil:

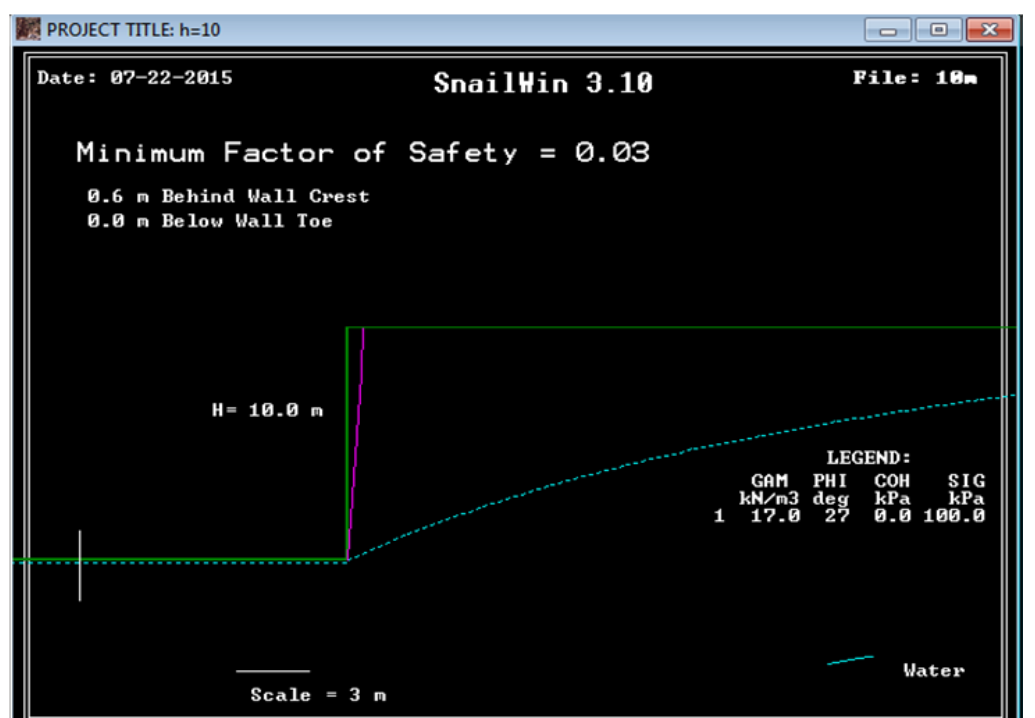

Figure 3. An example of the soil analysis in the state of applying water level in the absence of reinforced conditions- S-Nail software

Table 5. Analysis relating to applying elements

\begin{tabular}{ccccccc}
\hline Row & $\begin{array}{c}\text { length of } \\
\text { Nail }(\mathrm{m})\end{array}$ & $\begin{array}{c}\text { Grid } / \\
\text { density }\end{array}$ & $\phi$ & $\begin{array}{c}\mathrm{C} \\
\left(\mathrm{KN} / \mathrm{m}^{2}\right)\end{array}$ & $\begin{array}{c}\text { Bond stress } \\
(\mathrm{kPa})\end{array}$ & F.S \\
\hline 1 & & & 0 & 2 & & 0.04 \\
2 & & $2 \times 2$ & 32 & 2 & & 0.84 \\
3 & 6 & & 37 & 2 & 100 & 0.94 \\
4 & & \multirow{2}{*}{$1 \times 1$} & 37 & 2 & & 1.55 \\
5 & & & 32 & 2 & & 1.38 \\
6 & & & 0 & 2 & & 0.04 \\
7 & \multirow{2}{*}{6} & \multirow{2}{*}{$2 \times 2$} & 32 & 2 & & 0.88 \\
8 & & & 32 & 2 & 150 & 1.00 \\
9 & \multirow{2}{*}{10} & & 37 & 2 & & 1.11 \\
10 & & & & & & 1.23 \\
\hline
\end{tabular}

it is observed in the Table 5 that initially analysis in the state of fully saturation conducted that due to low F.S of soil resistive parameters increased, as is clear from the table soil just in the case of density has provided the desired 1x1 F.S and even increase in the length of Nails in state of $2 \times 2$ density has not been caused of achieving desired confidence coefficient.

\section{Pit depth of 20 meters:}

Allowed length of nail in the depth of Pit, according to the regulation of FHWA (2003), is 12 meters.

\section{Dry state:}

Initially soil was investigated in the dry state the details of which can be seen in Table 6:

Table 6. Assessing the Sustainability of unreinforced soil

\begin{tabular}{cccc}
\hline Row & $\varphi$ & $\mathrm{C}\left(\mathrm{KN} / \mathrm{m}^{2}\right)$ & F.S \\
\hline 1 & 32 & 1 & 0.12 \\
2 & 37 & 2 & 0.19 \\
\hline
\end{tabular}


Table 7 shows the analysis carried out on the mentioned soil:

Table 7. The analysis relating to the applying elements

\begin{tabular}{ccccccc}
\hline Row & $\begin{array}{r}\text { length of } \\
\text { Nail (m) }\end{array}$ & Grid / density & $\phi$ & $\begin{array}{c}\mathrm{C} \\
\left(\mathrm{KN} / \mathrm{m}^{2}\right)\end{array}$ & $\begin{array}{c}\text { Bond stress } \\
(\mathrm{kPa})\end{array}$ & F.S \\
\hline 1 & \multirow{2}{*}{12} & $2 \times 2$ & 32 & 0 & & 0.74 \\
2 & & $1 \times 1$ & 37 & 2 & 100 & 1.41 \\
3 & & & 37 & 0 & & 1.39 \\
4 & 12 & $2 \times 2$ & 37 & 2 & & 0.85 \\
5 & 16 & & 37 & 2 & & 0.85 \\
6 & & & 37 & 2 & 150 & 1.45 \\
7 & \multirow{2}{*}{12} & $1 \times 1$ & 32 & 2 & & 1.29 \\
8 & & & 32 & 0 & & 1.27 \\
9 & & & 37 & 0 & & 1.43 \\
\hline
\end{tabular}

From the Table 7 can be found that initially modeling was conducted based on minimum soil resistive parameters defined and variables increased due to the lack of desired confidence coefficient defined and reached to the maximum value defined for mentioned soil desired that desired confidence coefficient was not provided, ultimately.

also increasing length of Nails in the case that soil properties have their maximum values was not caused of achieving desired F.S Therefore, as can be seen in the table increase in density of the Nails from $2 \times 2$ to $1 \times 1$ provides confidence coefficient desired in most cases.

\section{Applying the water level:}

Initially soil was investigated in the unreinforced state the details of which can be seen in Table 6:

Table 8. Assessing the Sustainability of unreinforced soil

\begin{tabular}{cccc}
\hline Row & $\varphi$ & $\mathrm{C}\left(\mathrm{KN} / \mathrm{m}^{2}\right)$ & F.S \\
\hline 1 & 32 & 1 & 0.12 \\
2 & 37 & 2 & 0.17 \\
\hline
\end{tabular}

Table 9 shows the analysis carried out on the mentioned soil:

Table 9. The analysis relating to the applying elements

\begin{tabular}{ccccccc}
\hline Row & $\begin{array}{c}\text { length of } \\
\text { Nail(m) }\end{array}$ & $\begin{array}{c}\text { Grid } / \\
\text { density }\end{array}$ & $\phi$ & $\begin{array}{c}\mathrm{C} \\
\left(\mathrm{KN} / \mathrm{m}^{2}\right)\end{array}$ & $\begin{array}{c}\text { Bond stress } \\
(\mathrm{kPa})\end{array}$ & F.S \\
\hline 1 & 12 & $1 \times 1$ & 37 & 2 & 100 & 1.32 \\
2 & & & 0 & 2 & & 0.02 \\
3 & 12 & $2 \times 2$ & 32 & 2 & & 0.71 \\
4 & & & 37 & 2 & & 0.80 \\
5 & 16 & & 37 & 2 & 150 & 0.80 \\
6 & 12 & $1 \times 1$ & 37 & 2 & & 1.36 \\
7 & 16 & & 32 & 2 & & 1.21 \\
8 & 16 & & 2 & & 1.38 \\
\hline
\end{tabular}

it is observed in the Table 9 that initially analysis in the state of fully saturation conducted that due to low F.S of soil resistive parameters increased, as is clear from the table soil just in the case of density has provided the desired 1x1 F.S and even increase in the length of Nails in state of $2 \times 2$ density has not been caused of achieving desired confidence coefficient. 


\section{Pit depth of 30 meters:}

Allowed length of nail in the depth of Pit, according to the regulation of FHWA (2003), is 18 meters.

\section{Dry state:}

Initially soil was investigated in the dry state the details of which can be seen in Table 10:

Table 10. Assessing the Sustainability of unreinforced soil

\begin{tabular}{cccc}
\hline Row & $\varphi$ & $\mathrm{C}\left(\mathrm{KN} / \mathrm{m}^{2}\right)$ & F.S \\
\hline 1 & 32 & 1 & 0.10 \\
2 & 37 & 2 & 0.16 \\
\hline
\end{tabular}

Table 11 shows the analysis carried out on the mentioned soil:

Table 11. The analysis relating to the applying elements

\begin{tabular}{ccccccc}
\hline Row & $\begin{array}{r}\text { length of } \\
\text { Nail(m) }\end{array}$ & Grid / density & $\phi$ & $\begin{array}{c}\mathrm{C} \\
\left(\mathrm{KN} / \mathrm{m}^{2}\right)\end{array}$ & $\begin{array}{c}\text { Bond stress } \\
(\mathrm{kPa})\end{array}$ & F.S \\
\hline 1 & 18 & & 32 & 0 & 100 & 0.50 \\
2 & $2 \times 2$ & 37 & 2 & & 0.73 \\
3 & 20 & & 37 & 2 & & 0.73 \\
4 & 18 & & 37 & 2 & 150 & 1.26 \\
5 & 20 & $1 \times 1$ & 37 & 2 & & 1.32 \\
6 & 22 & & 37 & 2 & & 1.35 \\
\hline
\end{tabular}

From the Table 7 can be found that initially modeling was conducted based on minimum soil resistive parameters defined and variables increased due to the lack of desired confidence coefficient defined and reached to the maximum value defined for mentioned soil desired that desired confidence coefficient was not provided, ultimately. also increasing length of Nails in the case that soil properties have their maximum values was not caused of achieving desired F.S Therefore, as can be seen in the table increase in density of the Nails from $2 \times 2$ to $1 \mathrm{x} 1$ provides confidence coefficient desired increasing the density and length of Nails in situations that soil have had maximum values of $\mathrm{C}$ and $\varphi$.

\section{Applying the water level:}

Initially soil was investigated in the unreinforced state the details of which can be seen in Table 12:

Table 12. Assessing the Sustainability of unreinforced soil

\begin{tabular}{cccc}
\hline Row & $\varphi$ & $\mathrm{C}\left(\mathrm{KN} / \mathrm{m}^{2}\right)$ & F.S \\
\hline 1 & 32 & 1 & 0.09 \\
2 & 37 & 2 & 0.15 \\
\hline
\end{tabular}

Table 13 shows the analysis carried out on the mentioned soil:

Table 13. The analysis relating to the applying elements

\begin{tabular}{ccccccc}
\hline Row & $\begin{array}{r}\text { length of } \\
\text { Nail (m) }\end{array}$ & $\begin{array}{c}\text { Grid } / \\
\text { density }\end{array}$ & $\phi$ & $\begin{array}{c}\mathrm{C} \\
\left(\mathrm{KN} / \mathrm{m}^{2}\right)\end{array}$ & $\begin{array}{c}\text { Bond stress } \\
(\mathrm{kPa})\end{array}$ & F.S \\
\hline 1 & 18 & $2 \times 2$ & 37 & 2 & & 0.01 \\
2 & 20 & & 37 & 2 & & 0.66 \\
3 & & & 0 & 2 & 0.66 \\
\hline
\end{tabular}




\begin{tabular}{|c|c|c|c|c|c|}
\hline 4 & 18 & \multirow{4}{*}{$1 \times 1$} & 37 & 2 & 0.19 \\
\hline 5 & 20 & & 37 & 2 & 1.24 \\
\hline 6 & 22 & & 37 & 2 & 1.25 \\
\hline 7 & 24 & & 37 & 2 & 1.25 \\
\hline
\end{tabular}

In Table 13 is observed that the analysis initially conducted in a state of fully saturated that have increased due to low F.S of soil resistive parameters as is clear from the table in the maximum density of Nails and the final values of soil resistive parameters has not been covered parapet stability has not been provided and increasing the length of Nails has not been caused of achieving required F.S.

\section{Discussion and Conclusion}

Based on the analyzes performed, finally some tables were presented to initial selection and estimation of stabilization plan that the tables of 14,15 and 16 show the proposal plans presented to stabilization of the pit depths of 10, 20 and 30 meters:

Table 14. Proposal Guide of stabilization plan to Pit 10-meter

\begin{tabular}{|c|c|c|c|c|c|c|c|c|}
\hline $\begin{array}{c}\text { grid / } \\
\text { density }\end{array}$ & $\begin{array}{c}\text { length } \\
\text { of Nail } \\
\text { (m) }\end{array}$ & F.S & $\begin{array}{c}\mathrm{C} \\
\left(\mathrm{KN} / \mathrm{m}^{2}\right)\end{array}$ & $\varphi$ & $\begin{array}{l}\text { Dry / } \\
\text { juicy }\end{array}$ & $\begin{array}{c}\text { Overhead } \\
\text { / no } \\
\text { overhead }\end{array}$ & $\begin{array}{l}\text { Reinforced / } \\
\text { Unreinforced }\end{array}$ & $\begin{array}{c}\text { pit } \\
\text { depth }\end{array}$ \\
\hline- & - & $0.07-0.17$ & $1-2$ & $32-37$ & Dry & No & \multirow{4}{*}{ Unreinforced } & \multirow{10}{*}{$\underset{\Xi}{\underline{\Xi}}$} \\
\hline- & - & $0.12-0.16$ & $1-2$ & $32-37$ & Juicy & \multirow[b]{3}{*}{ Overhead } & & \\
\hline- & - & $0.16-0.23$ & $1-2$ & $32-37$ & Dry & & & \\
\hline- & - & $0.15-0.19$ & $1-2$ & $32-37$ & Juicy & & & \\
\hline $2 * 2$ & $6-16$ & $0.84-1.11$ & $0-2$ & $32-37$ & Dry & \multirow{4}{*}{$\begin{array}{c}\text { No } \\
\text { overhead }\end{array}$} & \multirow{6}{*}{ Reinforced } & \\
\hline $1 * 1$ & 6 & 1.43 & 0 & 32 & & & & \\
\hline $2 * 2$ & $6-10$ & $0.04-1.23$ & $0-2$ & $0-37$ & Juicy & & & \\
\hline $1 * 1$ & 6 & $1.38-1.55$ & 2 & $32-37$ & & & & \\
\hline $1 * 1$ & 6 & $1.38-1.56$ & $0-2$ & $32-37$ & Dry & \multirow{2}{*}{ Overhead } & & \\
\hline $1 * 1$ & 6 & $1.32-1.46$ & 2 & $32-37$ & Juicy & & & \\
\hline
\end{tabular}

Table 15. Proposal Guide of stabilization plan to Pit 20-meter

\begin{tabular}{|c|c|c|c|c|c|c|c|c|}
\hline $\begin{array}{l}\text { grid / } \\
\text { density }\end{array}$ & $\begin{array}{l}\text { length } \\
\text { of Nail } \\
\text { (m) }\end{array}$ & F.S & $\begin{array}{c}\mathrm{C} \\
\left(\mathrm{KN} / \mathrm{m}^{2}\right)\end{array}$ & $\varphi$ & $\begin{array}{l}\text { Dry / } \\
\text { juicy }\end{array}$ & $\begin{array}{c}\text { Overhead } \\
\text { / no } \\
\text { overhead }\end{array}$ & $\begin{array}{l}\text { Reinforced / } \\
\text { Unreinforced }\end{array}$ & $\begin{array}{c}\text { pit } \\
\text { depth }\end{array}$ \\
\hline - & - & $0.12-0.19$ & $1-2$ & $32-37$ & Dry & No & \multirow{4}{*}{ Unreinforced } & \multirow{10}{*}{$\stackrel{\Xi}{\Xi}$} \\
\hline - & - & $0.12-0.13$ & $1-2$ & $32-37$ & Juicy & overhead & & \\
\hline - & - & $0.12-0.17$ & $1-2$ & $32-37$ & Dry & & & \\
\hline - & - & $0.11-0.17$ & $1-2$ & $32-37$ & Juicy & Uvernead & & \\
\hline $2 * 2$ & $12-16$ & $0.74-0.85$ & $0-2$ & $32-37$ & Dry & & \multirow{6}{*}{ Reinforced } & \\
\hline $1 * 1$ & 12 & $1.27-1.45$ & $0-2$ & $32-37$ & & No & & \\
\hline $2 * 2$ & $12-16$ & $0.02-0.8$ & 2 & $0-37$ & Juicy & overhead & & \\
\hline $1 * 1$ & $12-16$ & $1.21-1.38$ & 2 & $32-37$ & & & & \\
\hline $1 * 1$ & 12 & $1.26-1.39$ & $0-2$ & $32-37$ & Dry & \multirow{2}{*}{ Overhead } & & \\
\hline $1 * 1$ & 12 & $1.07-1.3$ & 2 & 37 & Juicy & & & \\
\hline
\end{tabular}


Table 16. Proposal Guide of stabilization plan to Pit 30-meter

\begin{tabular}{|c|c|c|c|c|c|c|c|c|}
\hline $\begin{array}{l}\text { grid / } \\
\text { density }\end{array}$ & $\begin{array}{l}\text { length } \\
\text { of Nail } \\
\text { (m) }\end{array}$ & F.S & $\begin{array}{c}\mathrm{C} \\
\left(\mathrm{KN} / \mathrm{m}^{2}\right)\end{array}$ & $\varphi$ & $\begin{array}{l}\text { Dry / } \\
\text { juicy }\end{array}$ & $\begin{array}{l}\text { Overhead } \\
\text { / no } \\
\text { overhead }\end{array}$ & $\begin{array}{c}\text { Reinforced / } \\
\text { Unreinforced }\end{array}$ & $\begin{array}{c}\text { pit } \\
\text { depth }\end{array}$ \\
\hline- & - & $0.1-0.16$ & $1-2$ & $32-37$ & Dry & No & \multirow{4}{*}{ Unreinforced } & \multirow{10}{*}{$\underset{\mathbb{E}}{\text { III }}$} \\
\hline- & - & $0.1-0.15$ & $1-2$ & $32-37$ & Juicy & nead & & \\
\hline- & - & $0.09-0.15$ & $1-2$ & $32-37$ & Dry & \multirow{2}{*}{ Overhead } & & \\
\hline- & - & $0.09-0.14$ & $1-2$ & $32-37$ & Juicy & & & \\
\hline $2 * 2$ & $18-20$ & $0.5-0.73$ & $0-2$ & $32-37$ & Dry & \multirow{4}{*}{$\begin{array}{c}\text { No } \\
\text { overhead }\end{array}$} & \multirow{6}{*}{ Reinforced } & \\
\hline $1 * 1$ & $18-22$ & $1.26-1.35$ & 2 & 37 & & & & \\
\hline $2 * 2$ & $18-20$ & 0.66 & 2 & 37 & & & & \\
\hline $1 * 1$ & $18-24$ & $0.19-1.25$ & 2 & 37 & Juicy & & & \\
\hline $1 * 1$ & $20-25$ & $1.24-1.26$ & 2 & 37 & Dry & \multirow{2}{*}{ Overhead } & & \\
\hline $1 * 1$ & $23-30$ & $1.17-1.18$ & 2 & 37 & Juicy & & & \\
\hline
\end{tabular}

The above analysis shows that the sandy soil with medium density, in un- reinforcement conditions, at a depth of 10 meters pit, in both dry and humid, even in the most amount of soil resistance parameters has not gained the considered confidence coefficient.

At a depth of 10 meters pit and a lack of extra load, in both dry and humid, it is observed that the parapet when the parameters engineering of soil have been defined the greatest amount, the considered confidence coefficient is not supplied even with the maximum length and density in elements.

At a depth of 10 meters and in the absence of extra load, in the dry state, if the soil internal friction angle has been defined the maximum amount, with increasing network congestion of nails to $1 * 1$, the allowable confidence coefficient is obtained by the lowest allowable length of elements.

At a depth of 10 meters pit and in the presence of extra load, in both dry and humid states, increased density of elements network even with their minimum length provides the required confidence coefficient.

At a depth of 20 meters pit, in a un- reinforced conditions, in both dry and humid states, has not gained the considered confidence coefficient even in the most amount of soil resistance parameters.

At a depth of 20 meters pit and a lack of extra load, in the case of using $2 \times 2$ grids of nails, the allowed confidence coefficient cannot be achieved even with the greatest amount of resistance parameters of the soil and increased elements length.

At a depth of 20 meters pit, in both presence and absence of extra load, in dry and humid conditions, the allowed confidence coefficient is supplied just in case using nail density of $1 \times 1$.

At a depth of 20 meters PIT, and in the absence of extra load, and in the dry state and if the soil parameters have the highest defined value, the confidence coefficient is achieved at the nails density of $1 \times 1$.

At a depth of 20 meters pit, and in the absence of extra load, and in humid state, if the soil parameters have the highest defined value, in addition to the nails density of $1 \times 1$, their increased length provide the confidence coefficient.

At a depth of 20 meters pit, and in the presence of extra load, in both dry and humid states, if the soil parameters have the highest defined value, in the conditions of using Nails density of $1 \times 1$, with the minimum nail length, can supplied the allowed confidence coefficient.

At a depth of 30 meters pit, in a un- reinforced, in both dry and humid states, has not gained the confidence coefficient even in the most values of soil resistance parameters.

At a depth of 30 meters pit, without extra load conditions, in both dry and humid states, if the soil parameters and the length of using elements be the allowed maximum value, the required confidence coefficient cannot be achieved at the nail density of $2 \times 2$.

At a depth of 30 meters pit, without extra load conditions, in the dry state, if the soil parameters and the density grid of the nails be the maximum defined value, increased the length of elements provides the required 
confidence coefficient.

At a depth of 30 meters pit, without extra load conditions, in humid state, the confidence coefficient is not achieved, even if the soil parameters, and the length and density of nails be the maximum defined value.

At a depth of 30 meters pit, in presence of extra load conditions, in both dry and humid states, the confidence coefficient also is not achieved, even if the soil parameters, and the length and density of nails be the maximum defined value.

\section{References}

Bang, S., \& Chung, Y. (1999). The effect of the nail skew angle of soil nailing wall. KSCE Journal of Civil Engineering, 3(1), 73-79.

Byrne, R., Cotton, D., Porterfield, J., Wolschlag, C., \& Ueblacker, G. (1998). Manual for Design and Construction Monitoring of Soil Nail Wall, FHWA-SA-96-069R, Pages 30-65.

Hagen, D., Andenaes, E., \& Korstad, G. (1998), Innovative suction anchor design and installation. Offshore Technology Conference, Houston, Texas. Paper 8833.

Lazarte, C. A., Elias, V., Espinoza, R. D., \& Sabatini, P. J. (2003). Geotechnical Engineering Circular. Soil Nail Walls, (7), 5-42. Fhwa0- IF-03-017.

Nader, H. (2005). Stability analysis of earth slopes anchored by nailing. College of Engineering, 39(3), 415-426.

Pratap, Singh V., \& Sivakumar Babu, G. L. (2010). 2D Numerical Simulations of Soil Nail Walls. Geotech Geol Eng., (28), 299-309.

Renzi, R., \& Maggioni, W. (1994). Modelling the behaviour of skirt piles. Proceedings of the International Conference on the Behaviour of Offshore Structures, BOSS 94. Massuchusetts Institute of Technology, Cambridge, USA.

Seo, M., Olson, S., Yang, K., \& Kim, M. (2010). Sequential analysis of ground movements at three deep excavation sites with mixed ground profiles. Journal of Geotechnical and Geoenviromental Engineering, Eng., (136), 656-668.

\section{Copyrights}

Copyright for this article is retained by the author(s), with first publication rights granted to the journal.

This is an open-access article distributed under the terms and conditions of the Creative Commons Attribution license (http://creativecommons.org/licenses/by/3.0/). 